\title{
Leaf infiltration in plant science: old method, new possibilities
}

\author{
Izabela Anna Chincinska* (i)
}

\begin{abstract}
The penetration of substances from the surface to deep inside plant tissues is called infiltration. Although various plant tissues may be effectively saturated with externally applied fluid, most described infiltration strategies have been developed for leaves. The infiltration process can be spontaneous (under normal atmospheric pressure) or forced by a pressure difference generated between the lamina surface and the inside of the leaf. Spontaneous infiltration of leaf laminae is possible with the use of liquids with sufficiently low surface tension. Forced infiltration is most commonly performed using needle-less syringes or vacuum pumps.

Leaf infiltration is widely used in plant sciences for both research and application purposes, usually as a starting technique to obtain plant material for advanced experimental procedures. Leaf infiltration followed by gentle centrifugation allows to obtain the apoplastic fluid for further analyses including various omics. In studies of plant-microorganism interactions, infiltration is used for the controlled introduction of bacterial suspensions into leaf tissues or for the isolation of microorganisms inhabiting apoplastic spaces of leaves. The methods based on infiltration of target tissues allow the penetration of dyes, fixatives and other substances improving the quality of microscopic imaging. Infiltration has found a special application in plant biotechnology as a method of transient transformation with the use of Agrobacterium suspension (agroinfiltration) enabling genetic modifications of mature plant leaves, including the local induction of mutations using genome editing tools. In plant nanobiotechnology, the leaves of the target plants can be infiltrated with suitably prepared nanoparticles, which can act as light sensors or increase the plant resistance to environmental stress. In addition the infiltration has been also intensively studied due to the undesirable effects of this phenomenon in some food technology sectors, such as accidental contamination of leafy greens with pathogenic bacteria during the vacuum cooling process.

This review, inspired by the growing interest of the scientists from various fields of plant science in the phenomenon of infiltration, provides the description of different infiltration methods and summarizes the recent applications of this technique in plant physiology, phytopathology and plant (nano-)biotechnology.
\end{abstract}

Keywords: Leaf infiltration strategies, Syringe infiltration, Vacuum infiltration, Apoplast, Secretome, Phyllosphere, Agroinfiltration, Molecular farming, Infiltration in food industry, Nanomolecules

\section{Introduction}

The intercellular spaces in leaf mesophyll play a pivotal role in gas exchange and transpiration. Natural access to them is possible thanks to stomata on the leaf surfaces

*Correspondence: izabela.chincinska@ug.edu.pl

Department of Plant Physiology and Biotechnology, Faculty of Biology,

University of Gdańsk, ul. Wita Stwosza 59, 80-308 Gdańsk, Poland
[1-3]. Stomata are used to reach the intercellular spaces by pathogenic and non-pathogenic microorganisms which will inhabit the leaf intercellular space [4, 5]. Access to internal leaf tissues through the stomata also allows for the experimental application of various types of liquid substances from the outside. This procedure is commonly referred to as leaf infiltration [1, 6, 7]. Infiltration can occur spontaneously or as a forced process original author(s) and the source, provide a link to the Creative Commons licence, and indicate if changes were made. The images or other third party material in this article are included in the article's Creative Commons licence, unless indicated otherwise in a credit line to the material. If material is not included in the article's Creative Commons licence and your intended use is not permitted by statutory regulation or exceeds the permitted use, you will need to obtain permission directly from the copyright holder. To view a copy of this licence, visit http://creativecommons.org/licenses/by/4.0/. The Creative Commons Public Domain Dedication waiver (http://creativeco mmons.org/publicdomain/zero/1.0/) applies to the data made available in this article, unless otherwise stated in a credit line to the data. 
in which penetration of substances into the intercellular spaces is driven by the pressure difference between the surface and the inside of the leaf (Fig. 1). During the infiltration process, the gases present in the intercellular space are displaced by the applied liquid. Based on the number of scientific reports in which infiltration was described as one of the research techniques contributing to a larger experiment, it can be concluded that forced infiltration techniques are used more often than spontaneous techniques. Thus the term "infiltration" stands currently for the forced process in which different liquid substances are introduced into the plant tissue using equipment that generates a pressure gradient, such as a needle-less syringe (syringe infiltration) or a vacuum pump (vacuum infiltration) [8-10].

Plant infiltration techniques are useful in various fields of plant science, ranging from plant physiology, molecular physiology and biochemistry through biotechnology to applied plant sciences, such as plant cultivation, horticulture and agriculture [8,11-14]. Therefore, it appears that the application of various substances to the inside of the leaf tissues using infiltration techniques is carried out by researchers from seemingly disparate fields of plant biology to achieve various research goals. This review aims to bring together the methods used in plant biology in which infiltration is the starting procedure for further, sometimes very advanced research with the use

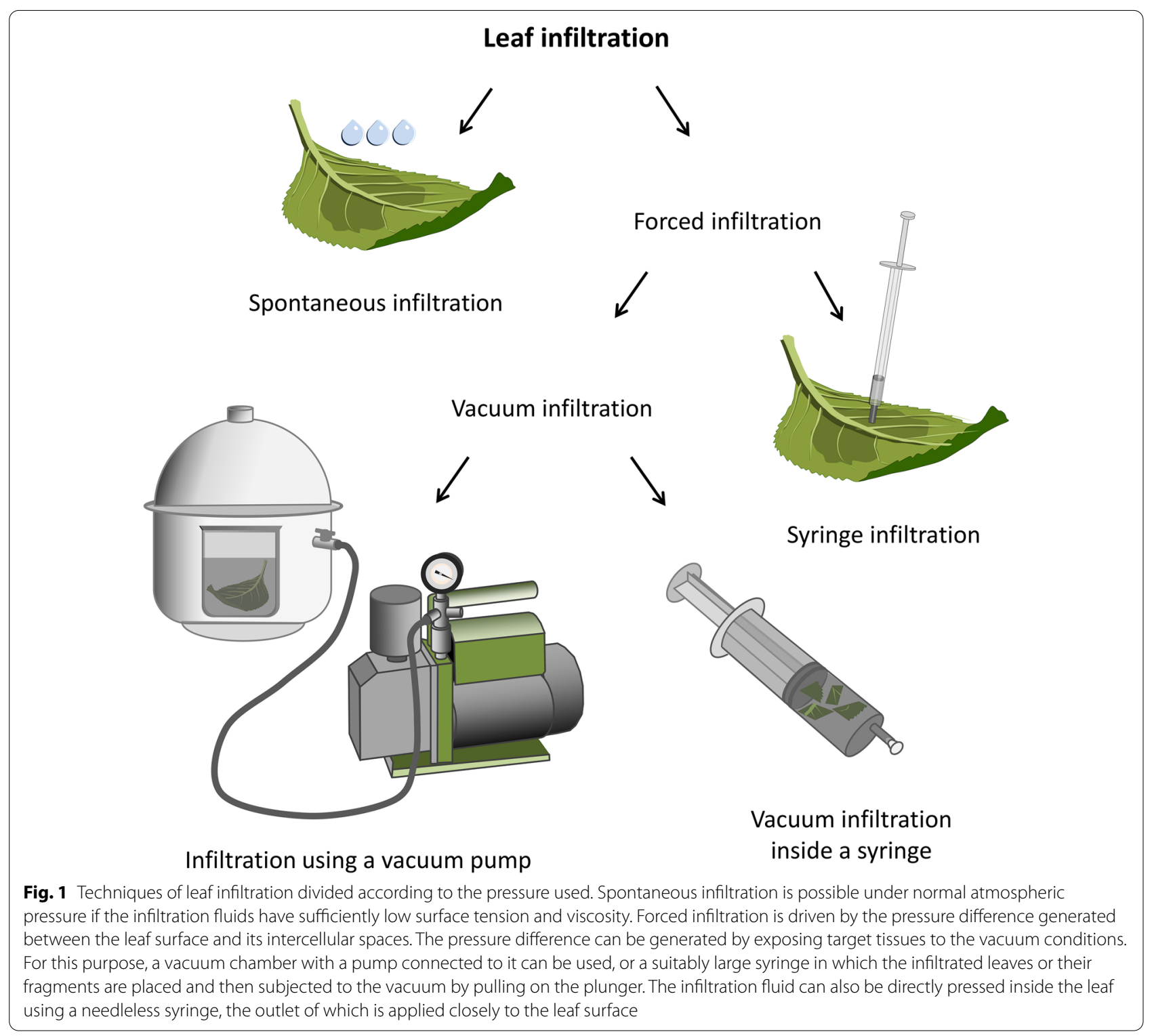


of modern laboratory equipment and the latest molecular technology. Due to the large variety of infiltration applications described in the latest literature and the expanding knowledge about its mechanisms, I have tried to classify and organize the information available on this subject. In the following sections I quote selected examples of research in which the procedure of application of liquid substances to the internal leaf tissue was introduced as a key preliminary procedure for larger experiments. This article also aims to inspire the development of novel leaf infiltration techniques and to search for new applications especially by those plant researchers who have not used infiltration in their work so far.

\section{Strategies of leaf infiltration}

The short term "infiltration" was originally used to describe the phenomenon of spontaneous penetration of liquids through the stomata into the intercellular spaces connected with stomatal cavities $[7,15]$. In the past, the spontaneous infiltration phenomenon was used to study stomatal functions, especially for the analysis of stomatal aperture and mechanisms of their control. The idea of using infiltration to study of stomata was first described at the beginning of the 20th century in two German-language publications $[7,16]$. In the brief version, the technique was based on treating the leaves of various plant species with low surface tension liquids such as ethanol, xylene, turpentine oil or benzene, which showed different rates of spontaneous penetration into leaf tissues. While almost fully open stomata were required for alcohol spontaneous infiltration, benzene could penetrate even the very slightly open stomata, which was clearly shown for several dozen of the plant species tested [7]. In the decades that followed, the use of infiltration to study stomata has been modified and refined many times by various researchers $[17,18]$. A particularly important modification was the replacement of the previously mentioned toxic substances by solutions with less destructive effects on the plant tissue [18]. Currently, those methods have rather historical value, because the study of stomatal functions is performed primarily using direct approaches, including modern microscopic techniques $[19,20]$. However, the experience gained over time and the results describing the mechanisms of spontaneous infiltration are still used in plant sciences, especially for practical applications. One of the examples is the use of non-toxic, non-fluorescent substances: perfluorocarbon (PFC), perfluorodecalin (PFD) and perfluoroperhydrophenanthrene (PP11) which improve the quality of in vivo plant leaf imaging, using for example laser scanning confocal microscopy (LSCM), two-photon fluorescence microscopy, second harmonic generation microscopy, and stimulated Raman scattering (SRS) microscopy [21]. Surface tensions of PFC, PFD and PP11 are significantly lower than the tension required to passively overcome the stomatal barrier, therefore they can be used for spontaneous infiltration of leaf tissue [17, 21]. During infiltration, the gases from the apoplastic space of the mesophyll are replaced by PFC, PFD or PP11 to create a homogeneous, undetectable filling of the leaf airspaces resulting in reduced noise and quantifiably clearer images [21]. The results of studies on the mechanisms of spontaneous infiltration are of particular use also when larger areas are subjected to foliar spraying with fertilizer, herbicides, plant protection products or growth regulators [22-26]. Spontaneous infiltration was recently used for introduction of cerium oxide nanoparticles (nanoceria) complexed with the surfactant Silwet L-77 (0.05\%) into cotton leaves, improving the salt tolerance of cotton plants [27].

For forced infiltration (Fig. 1), equipment that generates pressure changes is used to introduce fluid into the intercellular space. The simplest tool used for this purpose is a needle-free syringe. The inlet of a syringe filled with the appropriate liquid medium is placed directly on the surface of the leaf lamina, most commonly on the lower (abaxial) side due to the higher abundance of stomata, then the liquid is pressed into the leaf $[1,28]$. For larger-scale experiments, forced infiltration using a vacuum pump is a more suitable method. In contrast to syringe infiltration, the method using vacuum pomp is automated and therefore easier to control and more repeatable. Besides, the use of a vacuum pump allows infiltration of various organs and even entire plants. Plant tissues, immersed in the infiltration liquid, are placed in a vacuum chamber and subjected to reduced pressure. In the first phase of infiltration, lowering the pressure in the chamber leads to the release of gases from the stomatal cavities and the adjacent mesophyll airspaces through stomata and possibly through wounding sites [29]. Thus, the pressure within the leaf is lowered with a rate depending on the permeability of the mesophyll and the stomata opening to the gas flow [14]. Then, in the second phase of the process, the plant tissue undergoes rapid re-pressurization, during which the infiltration fluid is drawn into the intercellular space [30].

For very small plants, seedlings, small leaves or leaf fragments, a strategy in which the target tissues are placed together with the infiltration fluid inside a large syringe can also be applied. Pulling the plunger of the syringe, while blocking its opening, generates the negative pressure in the syringe chamber and in the infiltrated tissues. After unblocking the syringe opening and releasing the plunger, the pressure in the tissues is dynamically compensated by drawing the surrounding fluid inside the intercellular spaces $[2,6]$. The mechanism of such 
infiltration is similar to infiltration using a vacuum pump. Thus, the method is a simplified version of vacuum infiltration that can be carried out without access to a pump and a vacuum vessel $[2,6]$. Therefore, in the literature, both infiltration methods, driven by a vacuum pump and by a vacuum generated inside a syringe, are referred as "vacuum infiltration" $[2,6]$. By contrast, the term "syringe infiltration" (often called simply "infiltration") refers to a method in which the infiltration fluid is forced directly into the leaf lamina from a needleless syringe $[10,28,31$, 32].

In the case of syringe infiltration, the individual skills of the infiltrator and the parameters of the equipment used are of great importance. Syringe infiltration can cause mechanical stress, generating defence reactions in the plant organism which may interfere with or prevent the correct interpretation of the experimental results [9, 28]. Syringe infiltration is also less useful for large-scale application than vacuum infiltration because the method is laborious and time-consuming. Therefore, vacuum infiltration remains more frequently used than syringe infiltration due to its repeatability, the possibility of regulating the pressure value and its duration at each stage of infiltration [10]. Nevertheless, when precise local application of liquids inside the leaf is required, or when various substances need to be applied to multiple leaves on the mother plant, syringe infiltration is a more useful technique.

\section{Infiltration effectivity and monitoring methods}

The control of infiltration conditions was the subject of numerous studies and various reviews $[1,6,8,32]$. The factors influencing the effectiveness of infiltration can be divided into three groups: physicochemical properties of infiltration solutions, individual susceptibility of the infiltrated tissue or so-called infiltrability [6], and environmental (external) factors (Fig. 2).

Among the physicochemical properties of the infiltration solution which facilitate its penetration into plant tissues, the most frequently mentioned are surface tension and viscosity. Increasing in the value of surface tension adversely affects the effectiveness of infiltration.

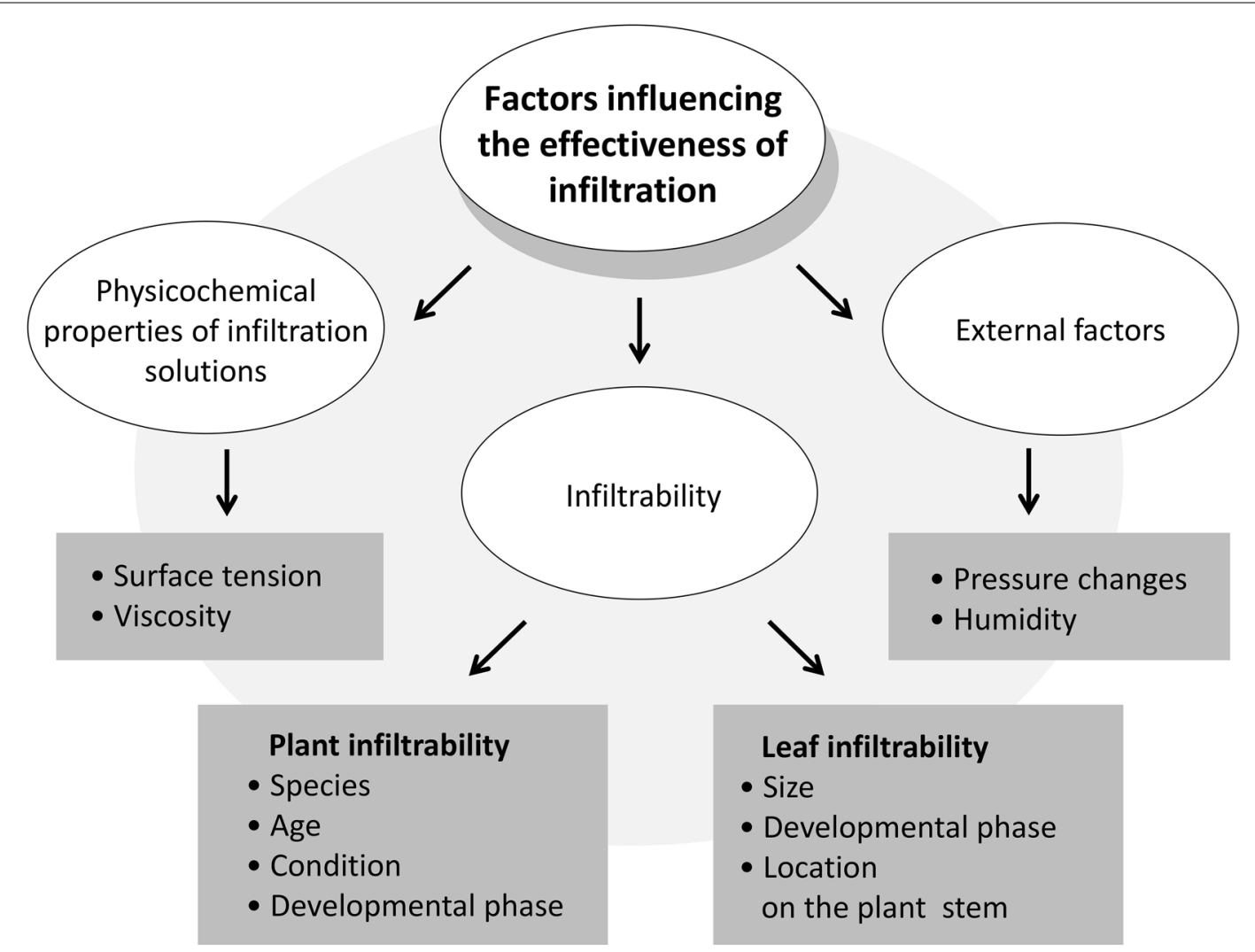

Fig. 2 Factors influencing the efficiency of leaf infiltration. All the factors that determine the effectiveness of leaf infiltration can be divided into three groups: 1. Physicochemical properties of an infiltration fluid, 2. Plant and leaf individual susceptibility to infiltration called infiltrability and 3. External factors. For each of these groups, the most important examples of factors are listed. If necessary, the poor infiltrability of plants and their individual leaves can be compensated by optimizing the composition of the infiltration fluid (group 1. factors) and the conditions of the infiltration period (group 3. factors) 
Liquids with high surface tension, including pure water, do not penetrate the inner leaf tissue without externally applied pressure $[7,17]$. The critical surface tension of $25-30 \mathrm{mN} / \mathrm{m}$ was determined experimentally for a model plant Zebrina purpusii by using a series of surfactant solutions of different surface tensions. It was shown that only fluids with surface tension below the critical value were able to spontaneously penetrate the stomata [17]. The addition of a surfactant is one of the ways to reduce the surface tension of the infiltration fluid. However, it is important that the final surfactant content is not higher than the critical micelle concentration (CMC). Otherwise, the viscosity of the infiltration fluid is increased $[17,33]$. The excessive fluid viscosity is also detrimental to the efficiency of infiltration $[18,26,33]$. This parameter is especially important for the infiltration of bacterial suspensions, because during their growth, the viscosity of the medium increases significantly due to excessive synthesis of exopolysaccharides [34]. The viscosity of bacterial suspensions can lowered by diluting the culture and/ or replacing the growth medium with an appropriate infiltration buffer, most often containing MES with the addition of magnesium salt and optional surfactants [32, $35,36]$.

Leaf infiltrability is dependent on its individual properties and generally is influenced by factors that affect the size, number and degree of opening of the stomata (thus infiltrability is subject to diurnal control), the chemical composition of the cutin and mesophyll resistance [2, $6,17,28]$. The parameters characterizing leaf infiltrability directly affect the value of the critical surface tension $[17,18]$. Many studies have confirmed that differences in infiltrability are related to plant species, age, condition, developmental phase, and are also largely dependent on the parameters that describe the individual leaves including leaf size, developmental phase or location on the plant stem $[6,28]$.

The most frequently discussed external factors influencing the infiltration process are pressure changes and humidity. In the first phase of vacuum infiltration a negative pressure is applied (the vacuum values between 20 and $25 \mathrm{kPa}$ are often used) [6,37]. During this stage, the pressure inside the leaf tissues decreases from atmospheric level to the target pressure at a rate depending on the permeability of the mesophyll as well as the resistance of the stomata to the gas flow [14]. Extending the duration of the first phase has a positive effect on the efficiency of infiltration until the pressure inside the infiltrated tissue reaches a value close to the applied external pressure [14, 29]. For Lactuca sativa valmaine, the substomatal cavity pressure reaches the target value after approximately 80,100 and $120 \mathrm{~s}$ with the applied vacuum of 45, 25 and $5 \mathrm{kPa}$, respectively [29]. Comparable results have been obtained by analyzing the mechanistic models for infiltration [14]. After reaching the target pressure value further extension of the duration of the first phase does not significantly affect the effectiveness of infiltration [14, 29]. During the re-pressurization phase, fluid penetrates into the intercellular spaces of the target tissues. The greater the pressure gradient between the inner spaces of the leaf and its outer surroundings, the deeper the penetration of the infiltration fluid and the faster the saturation of leaf airspaces [14, 29]. Simmons et al. demonstrated that the mass of liquid applied to leaves of $L$. sativa increased proportionally with vacuum intensity. Using a vacuum of $60,40,20$ and $5 \mathrm{kPa}$ resulted in infiltrating approximately $0.2,0.3,0.4$ and $0.5 \mathrm{~g}$ of bacterial suspension per $g$ of leaf tissue, respectively [29]. Also, the duration of the re-pressurization phase is very important for efficient infiltration. It was shown that during the repressurization from 0.7 to $100 \mathrm{kPa}$ for $1 \mathrm{~s}$, the amount of water that penetrated into the target tissue was almost $20 \%$ less than the amount of water when the re-pressurization time was $10 \mathrm{~s}$ [14]. Extending the re-pressurization time also increased the amount of bacteria that penetrated into the target tissue and the depth of their infiltration thus consequently, positively influenced the level of ectopic expression in the case of agroinfiltration [14, 38, 39].

The importance of moisture for the course of infiltration is interpreted ambiguously. On the one hand, it was suggested that low initial moisture content of the leaf leads to a stronger capillary diffusion of water in the vacuum infiltrated leaf tissues [14]. On the other hand, it is known that well-hydrated plants have open stomata and are much more susceptible to absorbing infiltration fluid forced into the leaf tissues using a needle-free syringe [28]. Due to the opening of the stomata, the optimal water content in the leaf tissues seems to be of fundamental importance for the optimization of the infiltration procedure [28]. Another important aspect is to maintain optimal humidity during the incubation of the leaves after infiltration. Depending on the experimental needs, immediately after infiltration the leaves can be subjected to reduced humidity to evaporate water from infiltration fluids, or increased humidity to stop the transpiration process $[28,40]$.

Various methods are performed to monitor the effectiveness of leaf infiltration. The simplest is visual evaluation. Infiltrated leaf tissues turn dark green at the site of the infiltration and the size of the dark spot depends on the leaf infiltrability $[6,28]$. It is relatively easy to recognize infiltration effects in the case of the vacuum infiltration strategy in which target explants become completely submerged in the fluid because the leaves or their fragments change colour when completely infiltrated with 
liquid and spontaneously sink into the solution [6]. The air spaces in tissue saturated with liquid are partly eliminated and reflected less light than non-infiltrated tissues, therefore, comparison of reflectivity of the infiltrated with the non-infiltrated leaves has also been proposed for evaluation of infiltration effectivity [41]. However, the most common way to monitor infiltration efficiency is to compare the leaf weight before and after infiltration. The increase in leaf weight as a result of saturation of air spaces with liquid enables assessment of the effectiveness of this process $[6,28,29]$. In the case of more advanced studies aimed at developing new infiltration methods or optimizing the infiltration conditions for plant species known for their poor infiltrability, various more technically advanced methods are recommended to direct observation of tissues impregnated with infiltration solutions. For this purpose, microscopic imaging or X-ray microtomography can be effectively used $[39,42]$.

\section{Infiltration in apoplast studies and in secretomics}

In secretome studies, especially in secretome proteomics, the isolation of good-quality apoplastic fluid is of particular importance [11, 43]. The most widely used procedure for this purpose is the infiltration-centrifugation method. The technique is amenable for the determination of metabolites and ions in the leaf apoplast and analysis of the plant secretome $[6,44]$. In this method, water or a suitably selected buffer is infiltrated into leaf tissue, then the whole leaves or large fragments of leaf are gently centrifuged to recover the so-called apoplast washing fluid (AWF) resulting from the dilution of the apoplastic fluid with infiltration medium $[2,6,44]$. The infiltration-centrifugation technique (in the case of vacuum infiltration-centrifugation the abbreviation VIC is usually used) allows for quick and easy collection of AWF from leaves. By optimizing the parameters of infiltration and centrifugation to individual needs and adjusting the appropriate infiltration buffer, it is possible to obtain good quality samples containing a representative composition of apoplastic fluid from intact leaves [2, 6, 44, 45]. The infiltration-centrifugation conditions can be adapted for applying the method to various plant species [6].

The AWF isolation method using the infiltration-centrifugation technique is gentle enough to allow minimal contamination of samples by damaged cells. To obtain the contamination-free apoplastic fluid samples, short infiltration times and low centrifugation forces are adjusted individually for target plant material $[2,6]$. In optimizing the procedure, various methods for detection of cytoplasmic contaminants in the collected AWF are used. For this purpose, measurements of the activity of marker enzymes such as malate dehydrogenase (MDH), glucosephosphate isomerase (GPI) and glucose-6-phosphate dehydrogenase (G6PDH), determination of the level of metabolites such as glucose-6-phosphate (G-6-P), or immunodetection of cytoplasmic proteins including $\mathrm{MDH}, \mathrm{RuBisCo}$ or ATPase are commonly used [2, 46, 47].

Another important parameter for assessing the AWF quality is the dilution factor because the infiltrationcentrifugation process leads to dilution of the apoplastic fluid [2]. Estimation of the dilution factor value is necessary to calculate the original concentrations of metabolites in the apoplastic fluid or when experiments requires the AWF concentration at full strength thus matching in vivo metabolite concentrations as accurately as possible, for example when AWF is used as an apoplast-mimicking growth medium for microbes [2]. For determining the AWF dilution factor, markers which are not absorbed, transported or modified after incorporation into the apoplast are used. An example is indigo carmine, which is added to the infiltration medium and measured spectrophotometrically in the obtained AWF at $610 \mathrm{~nm}$ [2]. Other substances such as blue dextran or $\left[{ }^{14} \mathrm{C}\right]$ sorbitol have also been used as AWF dilution markers [2, 6, 48].

The use of the infiltration-centrifugation method for apoplast studies has many advantages. One of the most important is that the method allows research on plants growing in natural or close to natural conditions. This is extremely important because the composition of the plant secretome depends on biotic and abiotic environmental conditions $[46,49,50]$. Such studies are therefore not possible using other secretome isolation techniques such as those in which the proteins released into the extracellular space are isolated from conditioned (postculture) media derived from hydroponic or plant cell cultures [51]. Therefore, the application of the infiltration-centrifugation for secretome sampling overcomes the inconveniences related to conducting plant cultures in vitro. An interesting aspect is the possibility of isolating plant secretome in response to climate change and/or environmental pollution using infiltration-centrifugation. This methodology was applied in a study of the detrimental effect of tropospheric ozone $\left(\mathrm{O}_{3}\right)$ on various plant species, showing significant protection of cells from $\mathrm{O}_{3}$ by ascorbate in leaf apoplast [52, 53]. In addition, using the infiltration-centrifugation method, secretome samples can be collected from large plants such as trees, or from species whose populations grow in large areas. It is most useful in studies of plants that occur naturally in particularly demanding, complicated environmental conditions where it is not possible to transfer the total research of such plants to the laboratory without simultaneously generating changes in the secretome.

The isolation of AWF by the infiltration-centrifugation method may also be useful for the analysis of 
recombinant proteins secreted into the apoplast of transgenic plants [54-56]. The effective isolation and purification of recombinant proteins from tissue of transgenic plants is one of the most critical points in developing plant expression systems as this step is costly and timeconsuming [57, 58]. Obtaining a pure recombinant product is crucial due to its biotherapeutic purpose and for planning its further applications [57, 58]. One of the most frequently used approaches towards increasing the efficiency of recombinant protein production is targeting them to various subcellular structures, including the apoplast [54-56, 59]. Proteins dissolved in the apoplastic fluid are much easier to extract and a higher yield can be obtained [2,54]. The use of the infiltration-centrifugation method has been recently proposed for the isolation of human recombinant DNase I secreted into the apoplast of transgenic tobacco and Luffa cylindrica plants [54].

\section{Research of plant-microorganism relationships}

The surface of above-ground organs of plants, known as the phyllosphere, is the habitat of numerous microorganisms $[60,61]$. The microbiome associated with the leaf phyllosphere is currently the subject of intensive research in various fields of plant biology and microbiology [62, 63]. Leaf infiltration is widely used in the research of plant disease mechanisms, where it has been developed for the controlled induction of plant infections, for example with the model prokaryotic pathogen Pseudomonas syringae, under standard laboratory conditions $[4,5,64]$. Although various bacteria and not only phytopathogens can actively penetrate the internal leaf tissues via stomata or tissue wounds, applying the inoculum to the leaf surface for spontaneous infiltration of microorganisms is a less efficient method than forced infiltration [20, 47, 65, 66]. Due to the need for spatially precise application of the inoculum and control of microbial load introduced into the plant tissue, it is preferable to use syringe infiltration for this purpose rather than vacuum infiltration $[4$, $5,12]$.

Leaf intercellular spaces, due to the presence of many nutritional compounds, optimal humidity and protection against the direct impact of external environmental conditions, provide unique habitats for various microorganisms, many of which are endophytes that are not considered pathogenic $[4,66]$. The colonization of plant organisms by bacterial or fungal endophytes can enhance resistance to biotic and abiotic stress, supporting the healthy growth and development of the plant hosts [12, 67]. For this reason, numerous attempts have recently been made to involve these endophytic microorganisms in the design of modern environmentally-friendly plant protection products $[68,69]$. Spontaneous and forced infiltration methods can be useful in the design and testing of bio-protection products containing microbes with an antagonistic effect on phytopathogens. These two infiltration techniques were used, for example, to test the protective effect of the insect pathogen Pseudomonas entomophila naturally inhabiting the soil, as it displayed a strong activity against the phytopathogenic bacteria Xanthomonas citri subsp citri $(X c c)$, the etiological agent of citrus canker disease [66]. Applying the mixture of $P$. entomophila and Xcc to the leaves using forced and spontaneous infiltration led to a significant reduction in the number of canker lesions in highly susceptible citrus leaves [66].

Studies of the microbes colonizing leaves are also of great importance in the field of bacteriological safety in the food industry $[63,70]$. It has been shown, for example, that although the enteric pathogen Salmonella enterica, is not a native plant endophyte, can actively infiltrate the deep leaf structures and multiply there [47]. Studying the diversity of microorganisms in endophytic communities and explaining the interactions between them can help to develop a strategy of the bacteriological protection of edible plants against their colonization with human pathogens. Another important reason for the study of leaf-phyllosphere microorganisms is their potential with regard to air purification from pollutants from anthropogenic and natural sources (phylloremediation) [63]. For the leaf microbiome studies, infiltration methods are used for example in experiments involving the introduction of various substances, including microorganism suspensions, into the apoplastic space to follow specific plant reactions or modifying their functions in a controlled manner [12]. Additionally, the infiltration-centrifugation method can be used to the extraction of AWF added to media prepared for endophyte microorganism cultured in vitro $[2,12]$.

Hong et al. emphasized the need for a detailed understanding of the molecular basis of the interactions between endophytes, phytopathogens and host plants. It seems particularly interesting to study the impact of these tripartite relationships on overall plant health [12]. Of particular importance for this type of research are those experiments which enable the tracking of these relationships in the natural environment in intact leaves. In particular, the technique has been useful in illustrating the occurrence of qualitative and quantitative differences in the plant microbiome depending on the conditions under which plants are grown $[4,63]$. The AWF extraction from leaves infiltrated with appropriate buffers can significantly improve this type of research. The infiltration-centrifugation method was used for the isolation of four novel endophytic bacteria from Arabidopsis thaliana [12]. In this experiment, plants were inoculated with Pseudomonas syringae pv. tomato 
DC3000 by syringe-infiltration, and a few days later the bacteria were isolated from the AWF derived from the upper uninfected leaves. Among the isolated microbes were members of Rhodococcus species that have never before been identified as leaf-inhabiting endophytes [12]. Further studies showed that the bacterial strains isolated from AWF can proliferate intercellularly in the leaf tissues of $A$. thaliana grown under sterile conditions. It has also been shown that the endophytic bacteria exhibit antagonistic activity against various phytopathogens, including Pseudomonas syringae pv. tomato DC3000 and Fusarium oxysporum pv. conglutinans [12].

Properly collected AWF contains at most only traces of cell contamination, so it is worth considering the use of infiltration-centrifugation as an attractive alternative to invasive methods of plant tissue homogenization used to study microorganisms inhabiting internal leaf tissues $[2,70]$. It is worth considering the adaptation of AWF extraction procedures towards using them as a starting material for culture-independent microbiome studies using, for example the Illumina Miseq platform. The material for metagenomic analyses obtained in this way could help to circumvent some of the basic problems encountered when using DNA derived from whole leaves macerated using standard protocols, including the low-throughput nature of plant tissue maceration and the prevalence of plant plastid DNA in metagenomic DNA extracts, which is typically coamplified via PCR strategies that target the bacterial 16S rRNA gene [70]. The method of pure AWF extraction for metagenomic DNA purification and library preparation could be helpful to overcome these problems. In addition, the optimization of the strategy for obtaining genetic material for metagenomic analyses from the AWF may increase the possibility of conducting metagenomic analyses in the environment, and in particular, facilitate the tracking of metagenome changes in real-time.

\section{Plant transformation}

Generation of genetically modified plants with the use of Agrobacterium carrying a binary vector containing genes of interest requires the penetration of the bacteria into the target tissues. Commonly, this procedure is carried out using plant in vitro cultures [71-73]. During the cocultivation step, Agrobacterium infiltrates leaves and cotyledons, which are the plant organs most often prepared as explants for transformation [30,74]. The effectiveness of bacterial suspension penetration into the target tissues can be increased by the use of tools driving forced infiltration. There are many examples of the use of the forced infiltration for improving the effectiveness of stable plant transformation in vitro. This method is of particular importance especially in the case of plant species for which it is difficult to establish a stable transformation protocol [71].

\section{Agroinfiltration}

In plant biotechnology, infiltration is most often associated with the popular and globally-used transient transformation technique of agroinfiltration, in which an Agrobacterium suspension is pressed into the target tissue of plants growing in planta. Agroinfiltration is widely used to test genetic constructs before they are introduced into stable lines and to study gene activity [75-79] or as a tool for the generation of plant expression platforms (plant biofactories) for recombinant protein production $[36,80-82]$. The use of agroinfiltration in the above-mentioned cases allows researchers to bypass the costly and time-consuming in vitro cultures. This is important not only for rapid induction of ectopic expression but also for avoiding the development of a generation of somaclonal variants, the formation of which during in vitro regeneration is problematic for the interpretation of phenotypic effects [78].

The successful introduction of Agrobacterium into leaf tissue is considered one of the most important requirements affecting the expression level of the foreign gene $[1,30,83]$. Leaves can be agroinfiltrated directly on the mother plant or after cutting $[8,28]$. Optimization of the agroinfiltration process involves the appropriate preparation of plant tissue to increase its infiltrability. Generally, plants intended for agroinfiltration must grow under optimal conditions conducive to the opening of the stomata and the formation of permeable mesophyll tissue. In the case of agroinfiltration of leaves separated from the mother plants (e.g., when leaves for agroinfiltration are collected in an open space from plants growing in different environmental conditions), the leaves can be incubated for a certain time under conditions conducive to the opening of the stomata immediately after harvest and before infiltrating [28]. Some agroinfiltration protocols introduce procedures supporting infiltrability [e.g., Sonication-assisted Agrobacterium-mediated transformation (SAAT)] that were tested previously during standard in vitro agrotransformation [84, 85]. It has been shown that treating tissues with ultrasound just before agroinfiltration can significantly increase the efficiency of this process $[35,84,86]$. In the case of plants that are very resistant to infiltration controlled wounding of target tissues is sometimes carried out, for example by repeated needle puncture of the leaf blade within the area where the infiltration will be carried out [87]. Depending on the target plant species and the bacterial strains used for transformation, optimization of the agroinfiltration procedure generally also requires adjusting the composition of the infiltration buffer and bacterial cell density. 
The physicochemical properties of an infiltration fluid are often adjusted based on knowledge gained decades ago from research on spontaneous infiltration [17, 32, 35].

The application of agroinfiltration allows for single and multigene transformations. As in the case of stable transformation, multigene constructs may be used for this purpose [88], but in general, it is much simpler to perform a co-infiltration with a mix of Agrobacterium strains carrying constructs containing different transgenes [31, 87, 89]. Theoretically, the number of the co-infiltrated constructs is unlimited, because the multigene transformation using agroinfiltration does not require selection markers, which are normally necessary for the regeneration of stably transformed plantlets. This is also a great advantage of agroinfiltration. Another way to obtain multigene expression is a method in which leaves of stable transgenic plants are agroinfiltrated with additional transgenes [90, 91].

In the case of agroinfiltration, there is no possibility of preselecting transformed tissues using antibiotics or herbicides. Despite this, it is possible to obtain a satisfactory level of foreign gene expression after applying appropriate procedures to optimize agroinfiltration $[1,28,87]$. In some experiments, for example, when the ectopically expressed gene leads to a pronounced hypersensitivity reaction [92], the effects of agroinfiltration are directly observable [35, 75, 92]. In turn, the direct microscopic observation of phenotype effects in agroinfiltrated leaves is possible in the subcellular localization tests using fusion constructs with reporter fluorescent proteins $[77,93]$. In this case, agroinfiltrated tissue sections can also be treated with cell wall degrading enzymes to obtain protoplasts [31]. The generation of protoplasts from agroinfiltrated tissues very often improves the quality of microscopic imaging and increases the sensitivity of the fluorescent signal detection. Interestingly, it was shown independently of agroinfiltration that infiltration techniques can be also used successfully to optimize protoplast preparation procedures. Introducing solutions containing cellulose and macerozyme directly to the intercellular space of Phaseolus vulgaris leaves using a vacuum significantly increased the yield of leaf mesophyll protoplasts [85]. When gene expression analysis using agroinfiltration does not allow the observation of direct phenotypic effects, it is necessary to use various foreign gene detection tools at the molecular level, including sequencing.

\section{Agroinfiltration in genome editing}

In recent years it has been shown that agroinfiltration of various plant species is applicable to test mutations induced at defined loci using various genome editing tools $[77,78,94]$. The use of agroinfiltration for genome editing can be a solution to bypass the problem of the generation of mutant plants in the case of mutations where the target gene proves to be lethal, and thus the regeneration of stably modified plant lines is impossible.

At the moment, the most popular genome-editing tool is the bacterial clustered regularly interspaced short palindromic repeats (CRISPR) system, comprising a CRISPR-associated 9 (Cas9) nuclease and an engineered single guide RNA (sgRNA) that specifies a targeted nucleic acid sequence. Nekrasov et al. described effective coexpression of the GFP-Cas9 gene and sgRNA using an Arabidopsis U6 promoter with the 20 bp guide sequence targeting the phytoene desaturase gene $(P D S)$ in agroinfiltrated $N$. benthamiana. Molecular analyses confirmed the induction of local mutations in PDS of agroinfiltrated tissue. Moreover, it was also shown that it is possible to regenerate plantlets containing mutations in the $P D S$ locus from the leaves transiently expressing the GFPCas 9 and sgRNA [77]. Such plant lines, regenerated from agroinfiltrated leaves, present mostly mosaic or heterozygous genotypes, however, they can be used for the production of seeds and consequently to obtain stable plant lines [77].

Another example of the effective use of agroinfiltration for genome editing in planta was described by $\mathrm{Ma}$ et al. [78]. Using the transcription activator-like effector nuclease (TALEN), the authors induced local mutations into the polyploid genome of two potato cultivars. Many researchers emphasize the importance of using TALEN as a system capable of generating a less off-target rate than the conventional CRISPR-Cas approach. This is of particular importance for successful gene knockout in polyploid organisms [78].

In both of the cases of gene editing strategy described above, it was not possible to directly observe the phenotypic effects. However, the restriction site mutation assay (RSM, restriction site loss assay) method proved to be useful for the initial detection and pre-selection of mutations in the agroinfiltrated tissues. The use of this molecular method is possible when dealing with the loss of the restriction site that was originally located at the edited gene. The use of the RSM assay allows for pre-scanning of agroinfiltrated tissues in terms of the content of induced mutations [78].

\section{Infiltration in molecular farming}

The production of recombinant proteins using plant organisms as expression systems is called molecular farming. In this rapidly developing field of plant biotechnology, infiltration techniques are used primarily to generate transient modified plant tissues by introducing Agrobacterium carrying foreign genes. The agroinfiltrated tissues thus become biofactories to produce recombinant 
proteins [10, 80-82, 95, 96]. Recombinant proteins are used in many fields of science, in particular in broadly understood medicine. So far, various recombinant proteins, vaccine components, enzymes, blood proteins and monoclonal antibodies have been produced in agroinfiltrated leaves [10, 36, 54, 80, 82, 97, 98].

Many of the recombinant proteins have multimeric structures and/or post-translational modifications necessary for their full activity. The multigene transformation strategies combining stable modification methods and agroinfiltration (co-infiltration using multiple genetic constructs) have gained particular importance in plant glycoengineering [91, 99-101]. The multigene modification enables for example the humanization of glycosylation patterns in the plant-derived recombinant proteins. For this purpose, methods for knockout or reduction of the expression of the native genes corresponding to typically plant post-translational modifications are used. In parallel, genes encoding human enzymes enabling the human-type modification of recombinant proteins are introduced to the plant genome. An example is a successful production of recombinant human immunoglobulin A (IgA) with defined $N$ - and $O$-glycans in planta [90, 99]. Due to the complicated multimeric structure and the presence of $\mathrm{N}$ - and $\mathrm{O}$-glycans, the production of recombinant IgA variants is one of the most difficult challenges in plant biotechnology. The in planta production of IgA was successful by combining agroinfiltration with stable transformation methods [56, 90]. For IgA production, glycoengineered $N$. benthamiana $\Delta \mathrm{XT} / \mathrm{FT}$ lines were used, in which the expression of two enzymes responsible for introducing typical plant modifications to the structure of $N$-glycans, the endogenous $\beta 1,2$ xylosyltransferase (XylT) and $\alpha 1,3$-fucosyltransferase (FucT), was stably reduced using RNA interference (RNAi) technology [56]. The $\triangle \mathrm{XT} / \mathrm{FT}$ lines were infiltrated with a mix of several different Agrobacterium strains carrying transgenes encoding the structural polypeptides forming double IgA and, also, proteins that do not build immunoglobulin structures but are relevant for the further posttranslational modifications necessary to obtain fully functional and homogeneous recombinant dimeric IgAs $[56,90]$.

\section{Infiltration in plant nanobiotechnology}

In recent years, the importance of the use of nanoparticles in various industries has grown, but at the same time, many studies indicate the harmfulness of nanoparticles to the environment $[80,102,103]$. The growing pollution of the environment by nanoparticles and their impact on plants is of serious concern. On the other hand, many research results show the possibility of using nanotechnology in agriculture and the food industry. Studies on both the positive and negative effects of nanoparticles on plants is often carried out in vivo, where one of the proposed methods of controlled application of nanoparticles to plants is foliar infiltration [104]. Leaf infiltration is also a method used to engineer plant nanobionic sensors for detection of environmental pollutants $[105,106]$.

The use of infiltration techniques for precise and homogeneous application of nanoparticle suspensions to leaf tissues was demonstrated with the example of thioglycolic acid-coated quantum dots (TGA-QD) with a cadmium telluride ( $\mathrm{CdTe}$ ) core and cadmium sulphide (CdS) shell. Due to their small size, versatile surface chemistry, and outstanding optical properties, quantum dots are recognized as an ideal model for plant nanobiotechnology research, especially for the study of nanoparticle uptake, transport, and distribution in plants by confocal microscopy tools [104]. However, the authors also suggest that the presented infiltration delivery methods can be extended to other nanomaterials, such as nanosensors or drug delivery carriers, having at least one dimension smaller than the plant cell wall porosity [104]. An example where the developed leaf infiltration procedure was used in nanobiotechnological research is the experiment in which increased salinity tolerance in Arabidopsis thaliana was induced by applying cerium oxide nanoparticles (nanoceria) inside the leaf [107]. The nanoceria exhibit the unique capability of catalytically reducing levels of stress-induced reactive oxygen species including hydroxyl radicals that lack enzymatic scavenging pathways. It was demonstrated that catalytic scavenging of hydroxyl radicals by nanoceria in $A$. thaliana leaves significantly improves mesophyll retention of $\mathrm{K}^{+}$ ions, which is crucial for increasing salinity stress tolerance [107].

\section{Infiltration in the food industry is not always a desirable phenomenon}

Recently, plant tissues infiltration mechanisms are being studied not only by researchers whose aim is to improve infiltration effectivity but also in research areas where infiltration is perceived as a very unfavourable process, for example in the food industry dealing with microbial food contamination [14, 20, 70].

Several bacteria, including Escherichia coli and Salmonella enterica, can infiltrate available openings at the leaf surface, such as stomata, cuts and wounds, penetrating the depths below the leaf epidermis [65]. Such contaminated vegetables are impossible to clean at home, which poses a threat to human health and life. The chemotactic penetration of bacteria into the intercellular spaces of leaves was thoroughly tested using a mechanistic model and confirmed experimentally on selected leaf vegetables. In these studies, light conditions conducive to 
photosynthesis, the presence of high initial sugar content levels due to pre-exposure of the leaf to light, high chemotactic ability of bacteria, and wide stomatal size were listed as the most important factors supporting bacterial infiltration into leafy vegetables [65].

Recent studies have also shown that vacuum cooling, which is widely used in the food industry, can promote infiltration of various contaminations that may be potentially present on food surfaces, including pathogenic microorganisms, such as norovirus, Salmonella and Escherichia coli $[14,20]$.

The vacuum is used as a rapid cooling technique applied especially to fruits, vegetables and in particular leafy greens [20]. The process of vacuum cooling is similar to the vacuum infiltration method used in plant science. During this process, the plant material is placed in a vacuum chamber and sprinkled with water to maintain good condition of the plants. The action of the reduced pressure generates intensive water evaporation resulting in a lower temperature [20]. As in the course of standard vacuum infiltration, during the re-pressurization step of vacuum cooling, water is pushed through the stomatal openings and the leaf mesophyll due to the large pressure gradients created within the leaf section [14]. When the vegetables have surface contaminants, these contaminants infiltrate the plant tissues via the water. From an epidemiological point of view, understanding this phenomenon is necessary for reducing food contamination. Therefore, it is currently being intensively studied and mathematical models have been developed to describe the infiltration process associated with vacuum cooling $[14,20]$. The developed models allow for a detailed interpretation of a wide range of factors known to affect the course of the infiltration process and for theoretical prediction of the infiltration efficiency after changing certain parameter [14, 20].

Other helpful tools are the models constructed for the vacuum impregnation process, another technology important for the food industry which is used to facilitate the impregnation of vegetable tissues with different solutions (e.g., solutions containing antioxidants, antimicrobial agents or cryoprotectants) to improve their performance properties or to extend their durability in long-term storage $[39,108,109]$. The described models may be useful in planning, optimizing and controlling the infiltration process to achieve optimal results and repeatability of the planned experiments in the broadly understood fields of plant science.

\section{Conclusions}

The techniques of leaf infiltration consisting of the application of various liquid substances into the intercellular spaces of the mesophyll through the openings of the stomata are widely used by plant researchers both for cognitive and application purposes (Table 1). On the basis of the examples described in this review, two categories of experiments using leaf infiltration techniques can be distinguished (Fig. 3). The first category includes experiments in which the application of various substances to the internal leaf tissues is intended to induce the studied effect (leaf infiltration as an input method), such as hormone application or agroinfiltration. The another category relates to the experiment aimed at characterization of the plant apoplast (leaf infiltration as an output method). In this case, after infiltration of the intercellular spaces with water or an appropriately selected buffer, the buffer is recovered in the form of fluid containing substances derived from the apoplastic leaf space. The apoplastic fluid obtained by this method can not only be subjected to further analyses by a wide range of omics techniques, but also be used to isolate and cultivate microorganisms inhabiting the intercellular leaf space. The use of infiltration as an output method can also be a way to monitor transgenic plants and to isolate the product of ectopic expression secreted into the apoplast. After studying many of the latest publications describing experiments in which the necessary initial stage was leaf lamina infiltration, it can be safely stated that infiltration is the equivalent of injection, which is the basic method used in scientific laboratories where research is carried out with animal models.

\section{Future prospects}

A well-performed infiltration technique (one which has high repeatability) is the basis for obtaining high-quality results in the output procedures. Therefore, the knowledge on the possibilities offered by infiltration and on the impact of different parameters on its effectiveness is crucial for the proper design of the experiment. Leaf infiltration methodology is widely used, but certainly not all infiltration possibilities have been discovered and used so far. Presumably, interest in effective leaf infiltration techniques will grow in the future. Especially agroinfiltration is considered to be a technology that will allow to establish plant bioreactors for efficient production of recombinant proteins used for therapeutic purposes and as vaccines. Recent developments in this field suggest that agroinfiltration-based molecular farming may be of particular importance in the future for the rapid and effective control of a pandemic of new, as yet unknown diseases.

For this kind of future use and in the context of the examples presented in this review it seems interesting and necessary to construct specialized infiltration equipment that would combine the advantages of syringe and vacuum infiltration. The design of such equipment and 


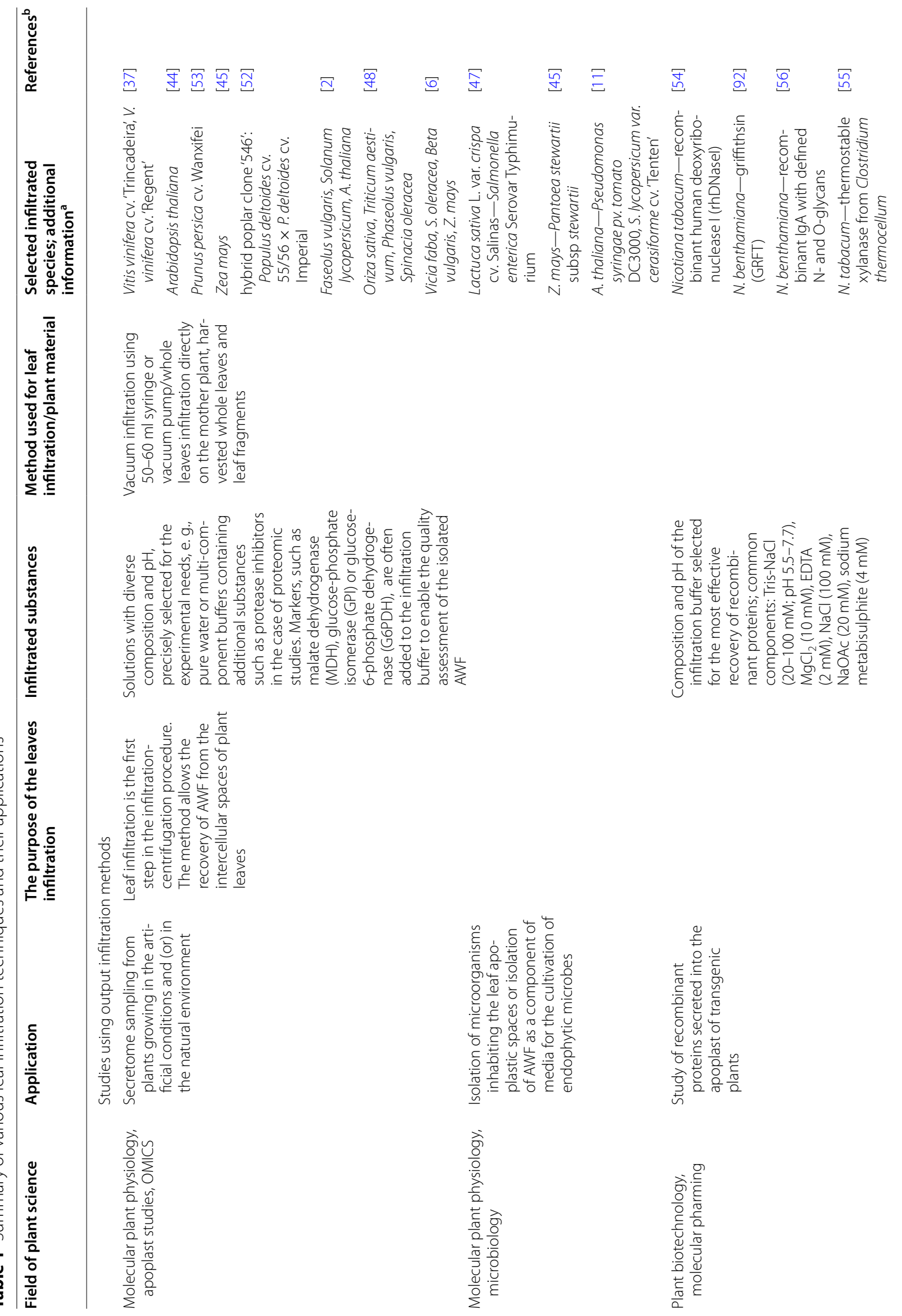




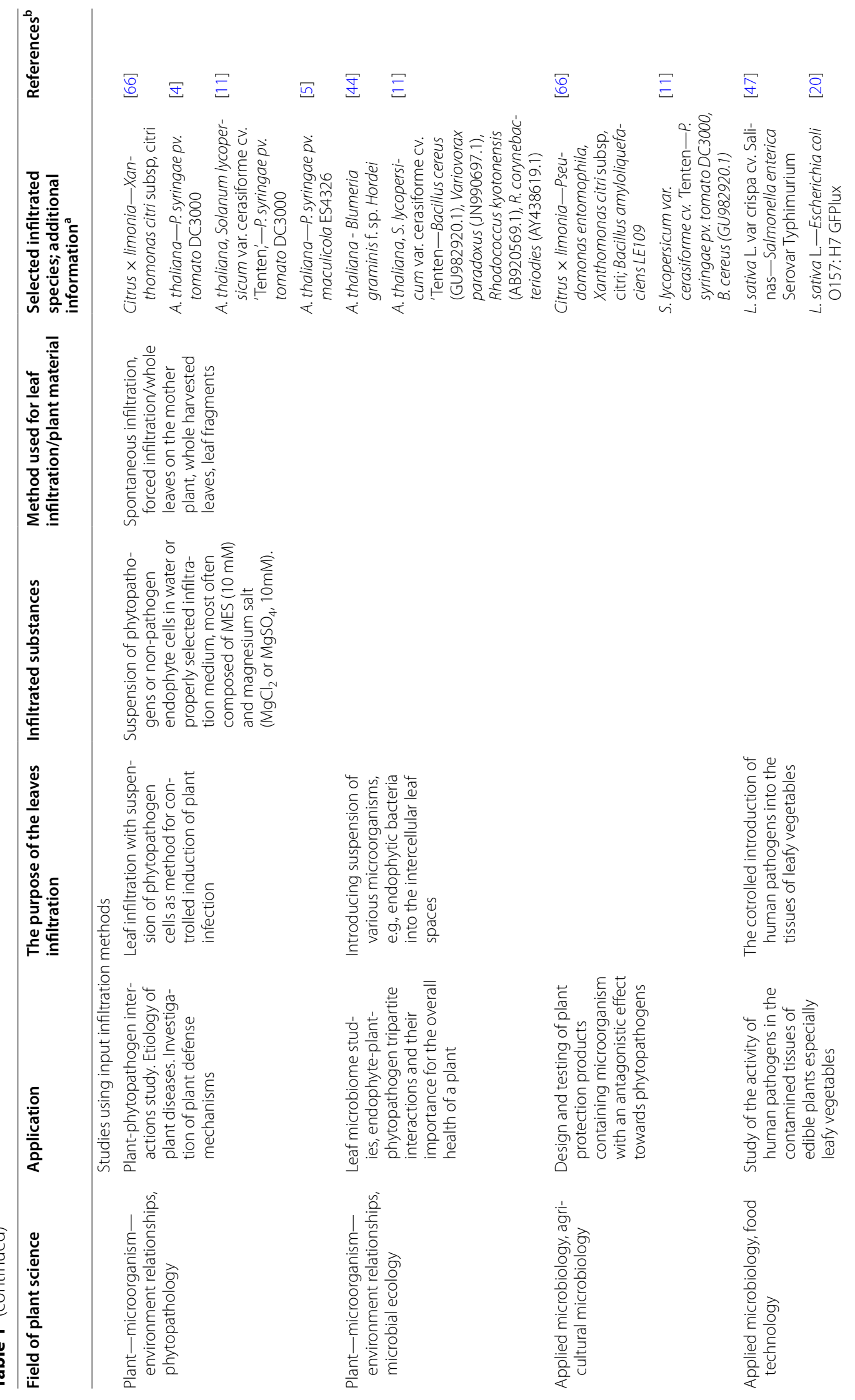




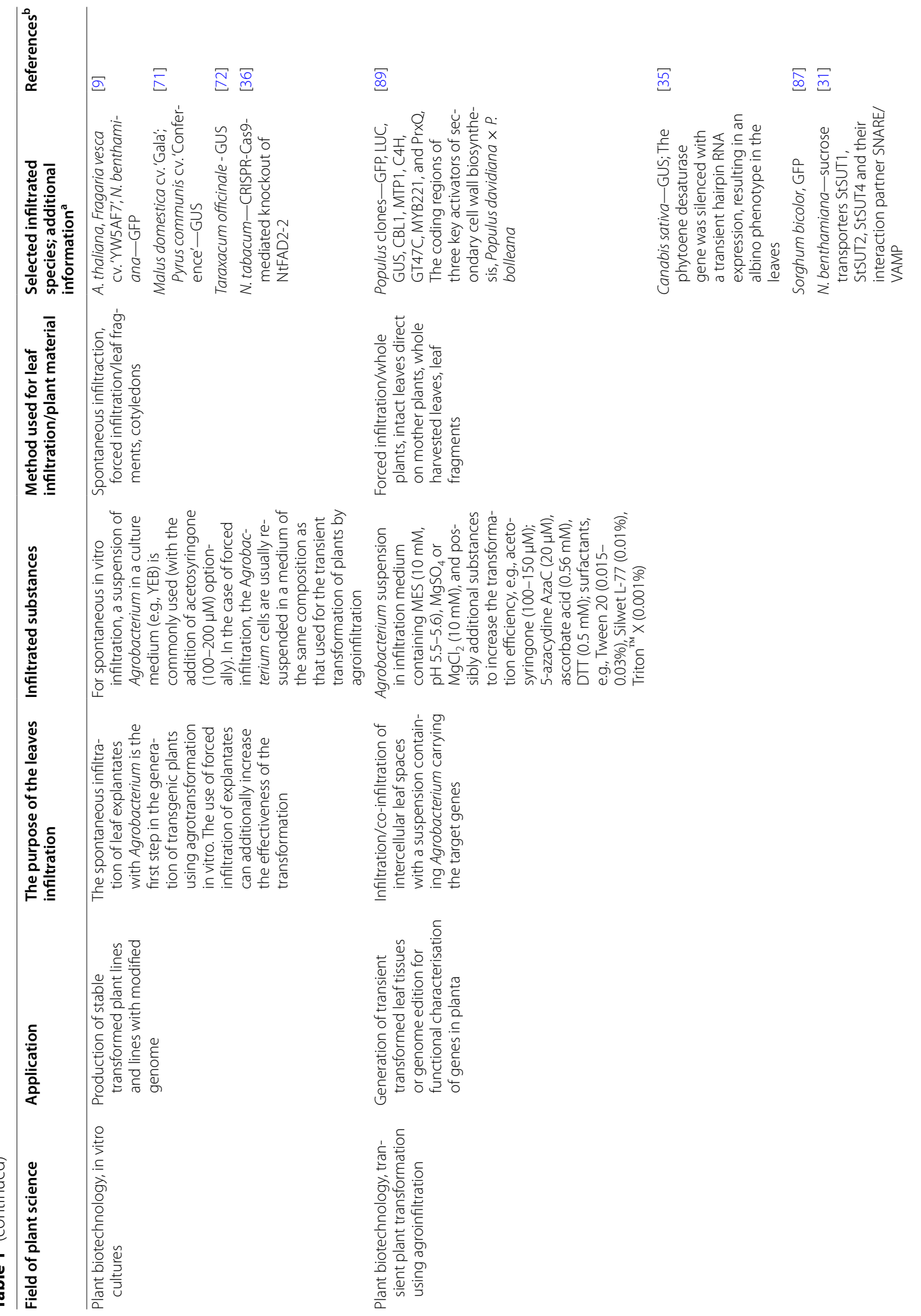




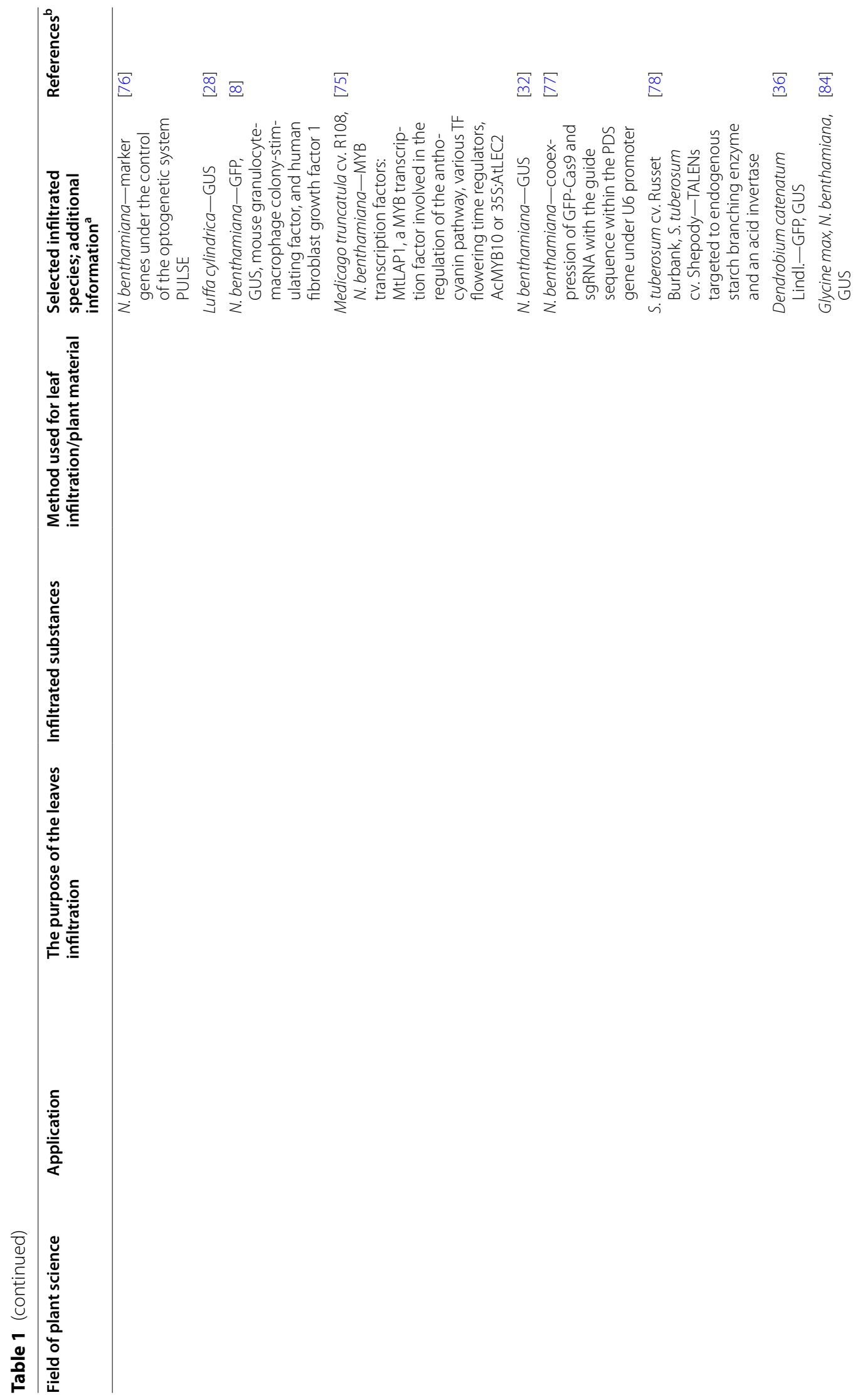




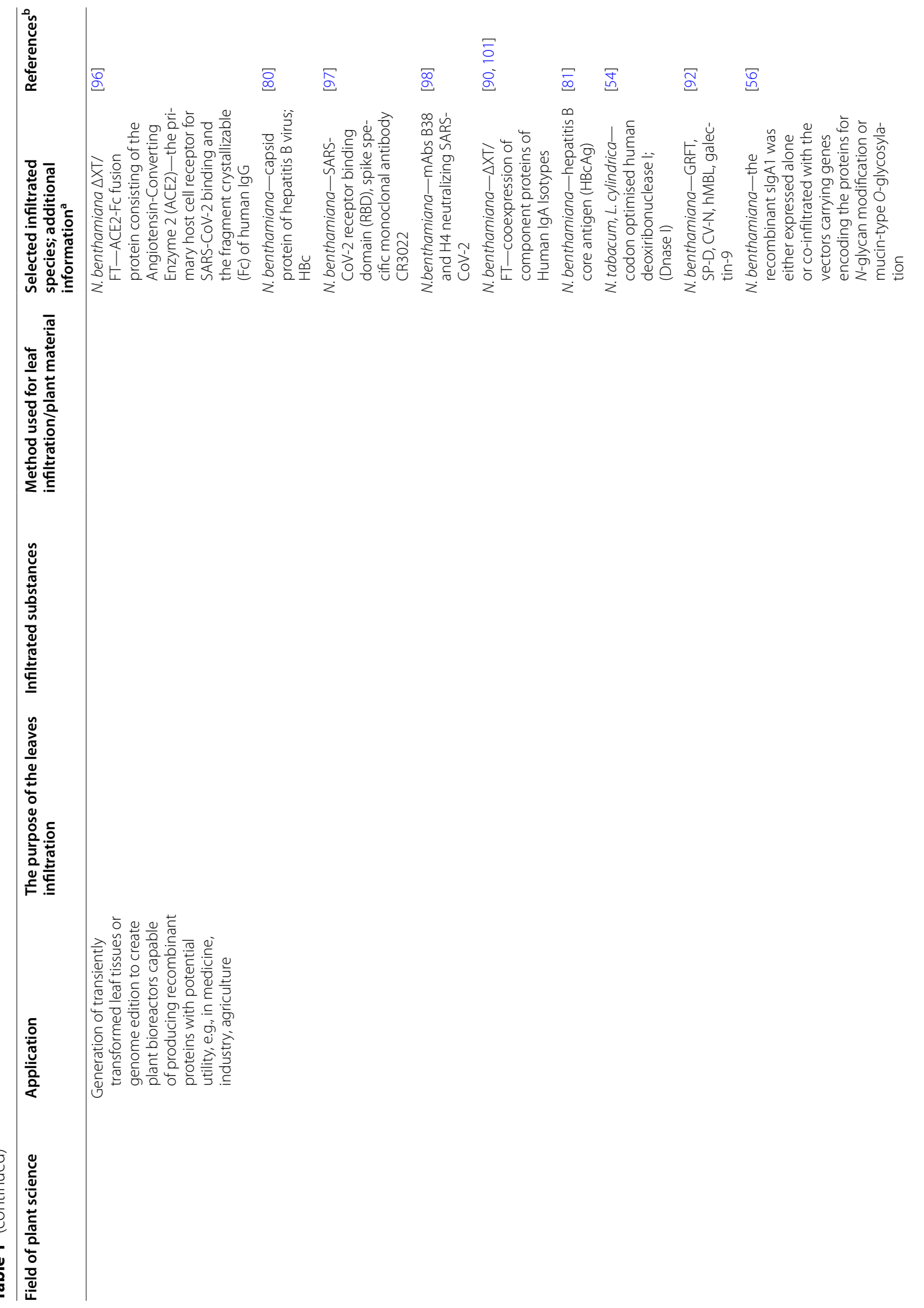




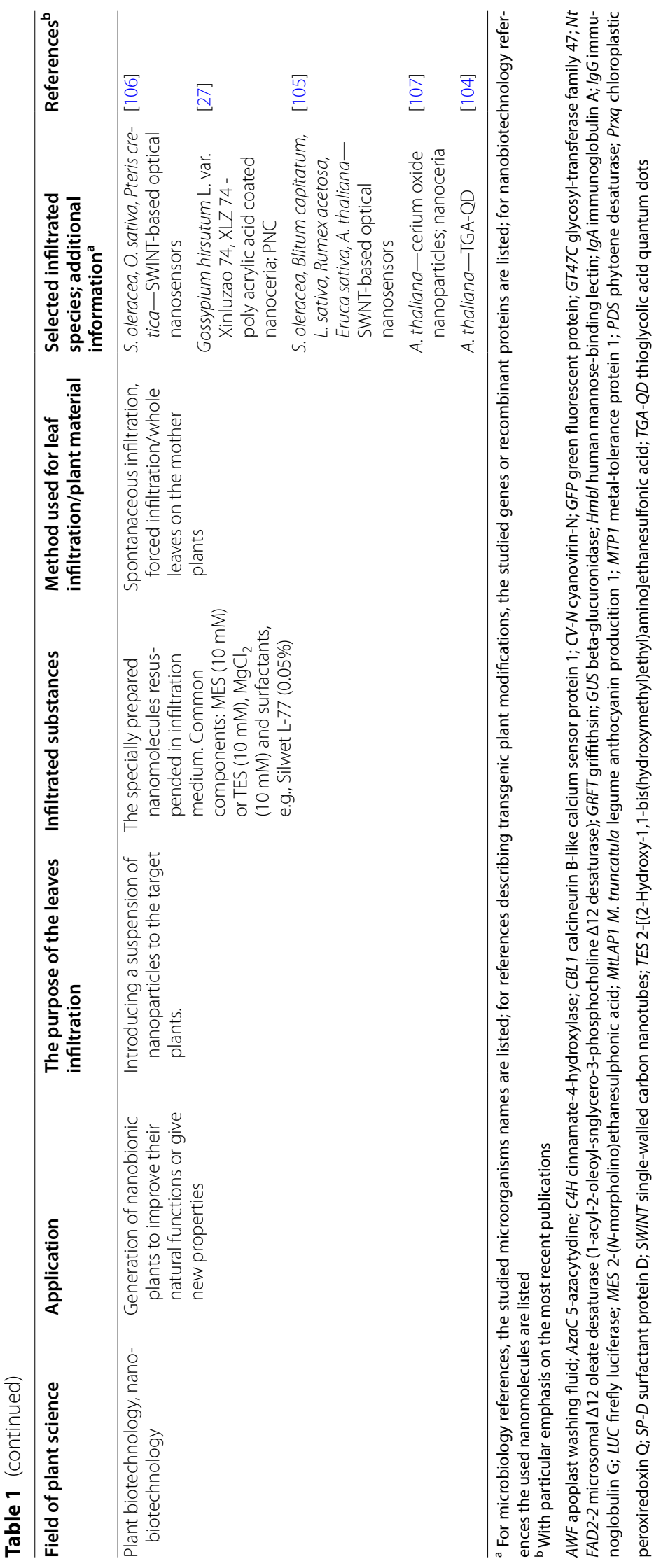




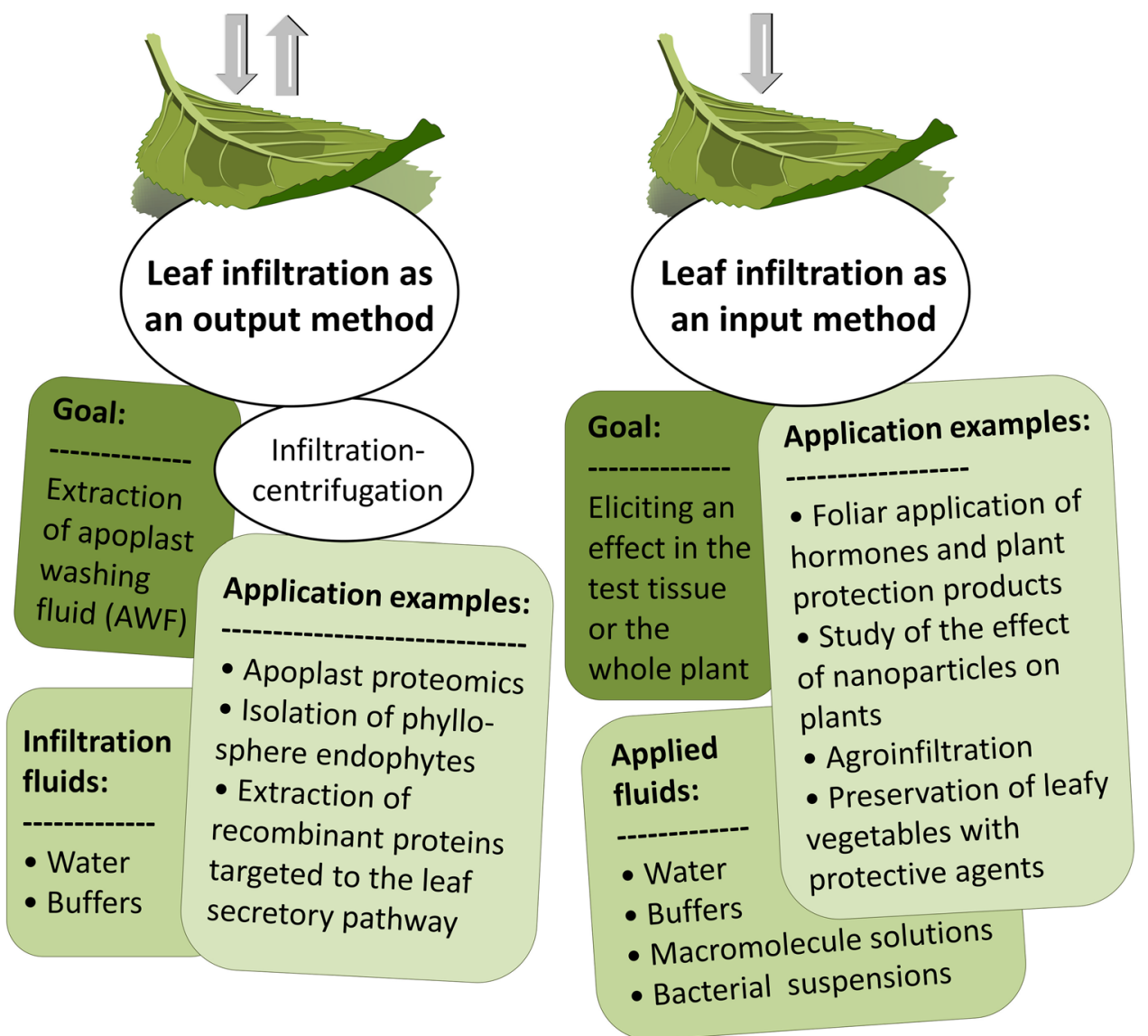

Fig. 3 Application of leaf infiltration-based methods in plant sciences. Two categories of experiments can be distinguished: 1. The infiltration as an output method in which leaves or their fragments after infiltration are centrifuged in order to recover the apoplastic fluid. The apoplastic fluid can be subjected to further analyses by a wide range of techniques. 2. The use of infiltration as an output method includes experiments in which the application of various substances to the internal leaf tissues is intended to induce the studied effect, such as hormone application or agroinfiltration

the optimization of its functions could largely be based on the results described so far $[1,9,10,14,28,65,108]$. Such a device should (1) be handy to use as a syringe, (2) allow convenient infiltration of even large leaves without the need to detach them from parent plants and cut them into pieces, (3) be small enough and easy to transport, which would enable its in field works, for example for infiltrating plants in their natural growth conditions, (4) generate minimal stress in the target plants. On the other hand, it is important that the infiltration with such equipment can be automated, while allowing for precise control of infiltration parameters. It would also be interesting to provide the leaf infiltration equipment with an additional function enabling the recovery of the infiltrated medium together with the apoplastic fluid (AWF) washed out from the intercellular spaces. The availability of this type of equipment would significantly increase the repeatability of experiments, which include infiltration both as an input and output method.

\begin{abstract}
Abbreviations
AWF: Apoplast washing fluid; AzaC: 5-Azacytydine; C4H: Cinnamate-4-Hydroxylase; CBL1: Calcineurin B-like Calcium Sensor Protein 1; CV-N: Cyanovirin-N; GFP: Green fluorescent protein; GT47C: Glycosyl-transferase family 47; $N t$ FAD2-2: Microsomal $\Delta 12$ oleate desaturase (1-acyl-2-oleoyl-snglycero-3-phosphocholine $\triangle 12$ desaturase); GRFT: Griffithsin; GUS: beta-Glucuronidase; Hmbl: Human mannose-binding lectin; IgA: Immunoglobulin A; IgG: Immunoglobulin G; LUC: Firefly luciferase; MES: 2-(N-morpholino)ethanesulphonic acid; MtLAP1: M. truncatula Legume anthocyanin producition 1; MTP1: Metal-tolerance protein 1; PDS: Phytoene desaturase; Prxq: Chloroplastic peroxiredoxin Q; SP-D: Surfactant protein D; SWINT: Single-walled carbon nanotubes; TES: 2-[(2-Hydroxy-1,1-bis(hydroxymethyl)ethyl)amino]ethanesulfonic acid; TGAQD: Thioglycolic acid quantum dots.
\end{abstract}

\section{Acknowledgements}

I would like to thank Dr. Magdalena Miklaszewska for many valuable comments and the English proofreading of the text. I gratefully acknowledge Dr. hab. Anna Aksmann, Dr. hab. Christina Kühn for the sincere support.

\section{Authors' contribution}

The author contributed fully to this review by selecting and studying the source literature, writing the manuscript and preparing the figures. The author 
read and approved the final manuscript. The author read and approved the final manuscript.

\section{Funding}

Not applicable.

\section{Availability of data and materials}

Not applicable.

\section{Declarations}

Ethics approval and consent to participate

Not applicable.

\section{Consent for publication}

Not applicable.

\section{Competing interests}

The author declares that she has no competing interests.

Received: 19 January 2021 Accepted: 11 July 2021

Published online: 28 July 2021

\section{References}

1. Leuzinger K, Dent M, Hurtado J, Stahnke J, Lai H, Zhou X, et al. Efficient agroinfiltration of plants for high-level transient expression of recombinant proteins. J Vis Exp. 2013;77:1-9.

2. O'Leary BM, Rico A, McCraw S, Fones HN, Preston GM. The infiltrationcentrifugation technique for extraction of apoplastic fluid from plant leaves using Phaseolus vulgaris as an example. J Vis Exp. 2014;94:e52113.

3. Knox JP. Cell adhesion, cell separation and plant morphogenesis. Plant J. 1992;2:137-41.

4. Karasov TL, Neumann M, Duque-Jaramillo A, Kersten S, Bezrukov I, Schröppel B, et al. The relationship between microbial population size and disease in the Arabidopsis thaliana phyllosphere. BioRxiv. 2020. https://doi.org/10.1101/828814.

5. Liu X, Sun Y, Kørner CJ, Du X, Vollmer ME, Pajerowska-Mukhtar KM. Bacterial leaf infiltration assay for fine characterization of plant defence responses using the Arabidopsis thaliana-Pseudomonas syringae pathosystem. J Vis Exp. 2015:104:1-12.

6. Lohaus G, Pennewiss K, Sattelmacher B, Hussmann M, Hermann MK. Is the infiltration-centrifugation technique appropriate for the isolation of apoplastic fluid? A critical evaluation with different plant species. Physiol Plant. 2001;111:457-65.

7. Molisch H. Das Offen-und Geschlossensein der Spaltöffnungen, varanschaulicht durch eine neue Methode (Infiltrationsmethode). Zeitschrift für Botanik 1912;6:106-22.

8. Matsuo K, Fukuzawa N, Matsumura T. A simple agroinfiltration method for transient gene expression in plant leaf discs. J Biosci Bioeng. 2016;122:351-6.

9. Mad'Atari MFB, Folta KM. Transformation improvement with the Standardized Pressure Agrobacterium Infiltration Device (SPAID). BMC Res Notes. 2019:12:144

10. Chen Q, Lai H, Hurtado J, Stahnke J, Leuzinger K, Dent M. Agroinfiltration as an effective and scalable strategy of gene delivery for production of pharmaceutical proteins. Adv Tech Biol Med. 2013:1:1.

11. Guerra-Guimarães L, Tenente R, Pinheiro C, Chaves I, Silva MD, Cardoso $\mathrm{FMH}$, et al. Proteomic analysis of apoplastic fluid of Coffea arabica leaves highlights novel biomarkers for resistance against Hemileia vastatrix. Front Plant Sci. 2015;6:478.

12. Hong CE, Jo SH, Moon JY, Lee JS, Kwon SY, Park JM. Isolation of novel leaf-inhabiting endophytic bacteria in Arabidopsis thaliana and their antagonistic effects on phytopathogens. Plant Biotechnol Rep. 2015:9:451-8.

13. Aiello D, Siciliano C, Mazzotti F, Di Donna L, Risoluti R, Napoli A. Protein extraction, enrichment and MALDI MS and MS/MS analysis from bitter orange leaves (Citrus aurantium). Molecules. 2020;25:1485
14. Ranjbaran M, Datta AK. Pressure-driven infiltration of water and bacteria into plant leaves during vacuum cooling: a mechanistic model. J Food Eng. 2019;246:209-23.

15. Alvim PDT, Havis JR. An improved infiltration series for studying stomatal opening as illustrated with coffee. Plant Physiol. 1954;29:97-8.

16. Stein E. Bemerkungen zu der Arbeit von Molisch: "Das Offenund Geschlossensein der Spaltöffnungen veranschaulicht durch eine neue Methode." Berichte der Deutschen Botanischen Gesellschaft.1912;30:66-8.

17. Schönherr J, Bukovac MJ. Penetration of stomata by liquids: dependence on surface tension, wettability, and stomatal morphology. Plant Physiol. 1972:49:813-9.

18. Hack HRB. The selection of an infiltration technique for estimating the degree of stomatal opening in leaves of field crops in the Sudan and a discussion of the mechanism which controls the entry of test liquids. Ann Bot. 1974;38:93-114.

19. Eisele JF, Fäßler F, Bürgel PF, Chaban C, Pandey GK. A rapid and simple method for microscopy-based stomata analyses. PLoS One. 2016;11:e0164576.

20. Vonasek E, Nitin N. Influence of vacuum cooling on Escherichia coli 0157: H7 infiltration in fresh leafy greens via a multiphoton-imaging approach. Appl Environ Microbiol. 2016;82:106-15.

21. Littlejohn GR, Mansfield JC, Christmas JT, Witterick E, Fricker MD, Grant $M R$, et al. An update: improvements in imaging perfluorocarbonmounted plant leaves with implications for studies of plant pathology, physiology, development and cell biology. Front Plant Sci. 2014;5:140.

22. Fernández V, Brown PH. From plant surface to plant metabolism: the uncertain fate of foliar-applied nutrients. Front Plant Sci. 2013;4:289.

23. Yang C, Powell CA, Duan Y, Shatters R, Zhang M, Spanoghe P. Antimicrobial nanoemulsion formulation with improved penetration of foliar spray through citrus leaf cuticles to control citrus Huanglongbing. PLoS ONE. 2015;10(7):e0133826.

24. Alshaal T, El-Ramady H. Foliar application: from plant nutrition to biofortification. Environ Biodivers Soil Secur. 2017;1:71-83.

25. Gao M, Zhou J, Liu H, Zhang W, Hu Y, Liang J, et al. Foliar spraying with silicon and selenium reduces cadmium uptake and mitigates cadmium toxicity in rice. Sci Total Environ. 2018;631-632:1100-8.

26. Fuehring HD, Mazaheri A, Bybordi M, Khan AKS. Effect of soil moisture depletion on crop yield and stomatal infiltration. Agron J. 1966:58:195-8.

27. Liu J, Li G, Chen L, Gu J, Wu H, Li Z. Cerium oxide nanoparticles improve cotton salt tolerance by enabling better ability to maintain cytosolic $\mathrm{K}^{+} / \mathrm{Na}^{+}$ratio. J Nanobiotechnol. 2021;19:153-69.

28. Błażejewska K, Kapusta M, Zielińska E, Tukaj Z, Chincinska IA. Mature luffa leaves (Luffa cylindrica L.) as a tool for gene expression analysis by agroinfiltration. Front Plant Sci. 2017;8:228.

29. Simmons CW, Vandergheynst JS, Upadhyaya SK. A model of Agrobacterium tumefaciens vacuum infiltration into harvested leaf tissue and subsequent in planta transgene transient expression. Biotechnol Bioeng. 2009;102:965-70.

30. Simmons CW, Nitin N, Vandergheynst JS. Rapid, in situ detection of Agrobacterium tumefaciens attachment to leaf tissue. Biotechnol Prog. 2012;28:1321-8.

31. Garg V, Hackel A, Kühn C. Subcellular targeting of plant sucrose transporters is affected by their oligomeric state. Plants. 2020;9:158.

32. Zhao $H$, Tan $Z$, Wen $X$, Wang $Y$. An improved syringe agroinfiltration protocol to enhance transformation efficiency by combinative use of 5-azacytidine, ascorbate acid and tween-20. Plants. 2017;6:9.

33. Liu K, Yang Q, Yang T, Wu Y, Wang G, Yang F, et al. Development of Agrobacterium-mediated transient expression system in Caragana intermedia and characterization of CIDREB1C in stress response. BMC Plant Biol. 2019;19:237.

34. Tokdar P, Wani A, Kumar P, George S. Process and strain development for reduction of brothviscosity with improved yield in coenzyme Q 10 fermentation by Agrobacterium tumefaciens ATCC 4452. Ferment Technol. 2013:2:1-6.

35. Deguchi M, Bogush D, Weeden H, Spuhler Z, Potlakayala S, Kondo T, et al. Establishment and optimization of a hemp (Cannabis sativa L.) agroinfiltration system for gene expression and silencing studies. Sci Rep. 2020;10:3504. 
36. Chen J, Wang L, Chen J, Huang J, Liu F, Guo R, et al. Agrobacterium tumefaciens-mediated transformation system for the important medicinal plant Dendrobium catenatum Lindl. Vitr Cell Dev Biol Plant. 2018;54:228-39.

37. Figueiredo J, Cavaco AR, Guerra-Guimarães L, Leclercq C, Renaut J, Cunha J, et al. An apoplastic fluid extraction method for the characterization of grapevine leaves proteome and metabolome from a single sample. Physiol Plant. 2021;171:343-57.

38. Shynkaryk MV, Pyatkovskyy TI, Yousef AE, Sastry SK. Gaseous ozone treatment of baby spinach within the existing production chain for inactivation of Escherichia coli O157:H7. J Food Eng. 2016;191:10-8.

39. Panarese V, Dejmek P, Rocculi P, Gómez GF. Microscopic studies providing insight into the mechanisms of mass transfer in vacuum impregnation. Innov Food Sci Emerg Technol. 2013;18:169-76.

40. Fujiuchi N, Matsuda R, Matoba N, Fujiwara K. Removal of bacterial suspension water occupying the intercellular space of detached leaves after agroinfiltration improves the yield of recombinant hemagglutinin in a Nicotiana benthamiana transient gene expression system. Biotechnol Bioeng. 2016;113:901-6. https://doi.org/10.1002/ bit.25854.

41. Gausman HW, Allen WA, Escobar DE. Refractive index of plant cell walls. Appl Opt. 1974;13:109-11.

42. Panarese V, Herremans E, Cantre D, Demir E, Vicente A, Gãmez Galindo F, et al. X-ray microtomography provides new insights into vacuum impregnation of spinach leaves. J Food Eng. 2016;188:50-7.

43. Guerra-Guimarães L, Pinheiro C, Chaves I, Barros DR, Ricardo CP. Protein dynamics in the plant extracellular space. Proteomes. 2016:4:22.

44. Nakano RT, Ishihama N, Wang Y, Takagi J, Uemura T, Schulze-Lefert P, et al. Apoplastic fluid preparation from Arabidopsis thaliana leaves upon interaction with a nonadapted powdery mildew pathogen. Methods Mol Biol. 2020:2139:79-88.

45. Gentzel I, Giese L, Zhao W, Alonso AP, Mackey D. A simple method for measuring apoplast hydration and collecting apoplast contents. Plant Physiol. 2019;179:1265-72.

46. Delaunois B, Jeandet P, Clément C, Baillieul F, Dorey S, Cordelier S. Uncovering plant-pathogen crosstalk through apoplastic proteomic studies. Front Plant Sci. 2014;5:249.

47. Montano J, Rossidivito G, Torreano J, Porwollik S, Sela Saldinger S, McClelland M, et al. Salmonella enterica serovar Typhimurium 14028s genomic regions required for colonization of lettuce leaves. Front Microbiol. 2020;11:6.

48. Nouchi I, Hayashi K, Hiradate S, Ishikawa S, Fukuoka M, Chen CP, et al. Overcoming the difficulties in collecting apoplastic fluid from rice leaves by the infiltration-centrifugation method. Plant Cell Physiol. 2012;53:1659-68

49. Uemura T, Nakano RT, Takagi J, Wang Y, Kramer K, Finkemeier I, et al. A Golgi-released subpopulation of the trans-Golgi network mediates protein secretion in Arabidopsis. Plant Physiol. 2019;179:519-32.

50. Ruhe J, Agler MT, Placzek A, Kramer K, Finkemeier I, Kemen EM. Obligate biotroph pathogens of the genus Albugo are better adapted to active host defense compared to niche competitors. Front Plant Sci. 2016;7:820

51. Kusumawati L, Imin N, Djordjevic MA. Characterization of the secretome of suspension cultures of Medicago species reveals proteins important for defense and development. J Proteome Res. 2008; 7:4508-20.

52. Xu W, Shang $B, X u Y$, Yuan $X$, Dore AJ, Zhao Y, et al. Effects of elevated ozone concentration and nitrogen addition on ammonia stomatal compensation point in a poplar clone. Environ Pollut. 2018;238:760-70.

53. Dai L, Kobayashi K, Nouchi I, Masutomi Y, Feng Z. Quantifying determinants of ozone detoxification by apoplastic ascorbate in peach (Prunus persica) leaves using a model of ozone transport and reaction. Glob Change Biol. 2020;26:3147-62.

54. Chincinska IA, Kapusta M, Zielińska E, Miklaszewska M, Błażejewska K, Tukaj Z. Production of recombinant human deoxyribonuclease I in Luffa cylindrica $\mathrm{L}$. and Nicotiana tabacum L.: evidence for protein secretion to the leaf intercellular space. Plant Cell Tissue Organ Cult. 2019;136:51-63.

55. Herbers K, Wilke I, Sonnewald U. A thermostable xylanase from Clostridium thermocellum expressed at high levels in the apoplast of transgenic tobacco has no detrimental effects and is easily purified. Nat Biotechnol. 1995:13:63-6.
56. Dicker M, Tschofen M, Maresch D, König J, Juarez P, Orzaez D, et al. Transient glyco-engineering to produce recombinant $\lg \mathrm{A} 1$ with defined $\mathrm{N}$ - and O-glycans in plants. Front Plant Sci. 2016;7:18.

57. Dirisala VR, Nair RR, Srirama K, Reddy PN, Rao KRSS, Kumar SSN, et al. Recombinant pharmaceutical protein production in plants: unraveling the therapeutic potential of molecular pharming. Acta Physiol Plant. 2017:39:1-9.

58. Schillberg S, Raven N, Spiegel H, Rasche S, Buntru M. Critical analysis of the commercial potential of plants for the production of recombinant proteins. Front Plant Sci. 2019;10:720.

59. Komarnytsky S, Borisjuk NV, Borisjuk LG, Alam MZ, Raskin I. Production of recombinant proteins in tobacco guttation fluid. Plant Physiol. 2000;124:927-34.

60. Doan HK, Ngassam VN, Gilmore SF, Tecon R, Parikh AN, Leveau JHJ. Topography-driven shape, spread, and retention of leaf surface water impact microbial dispersion and activity in the phyllosphere. Phytobiomes J. 2020;4:268-80.

61. Remus-Emsermann MNP, Schlechter RO. Phyllosphere microbiology: at the interface between microbial individuals and the plant host. New Phytol. 2018;218:1327-33.

62. Lindow SE, Leveau JH. Phyllosphere microbiology. Curr Opin Biotechnol. 2002;13:238-43.

63. Wei X, Lyu S, Yu Y, Wang Z, Liu H, Pan D, et al. Phylloremediation of air pollutants: exploiting the potential of plant leaves and leaf-associated microbes. Front Plant Sci. 2017:8:1318.

64. Gimenez-lbanez S, Boter M, Ortigosa A, García-Casado G, Chini A, Lewsey MG, et al. JAZ2 controls stomata dynamics during bacterial invasion. New Phytol. 2017;213:1378-92.

65. Ranjbaran M, Solhtalab M, Datta AK. Mechanistic modeling of lightinduced chemotactic infiltration of bacteria into leaf stomata. PLoS Comput Biol. 2020;16:1007841.

66. Villamizar S, Ferro JA, Caicedo JC, Alves LMC. Bactericidal effect of entomopathogenic bacterium Pseudomonas entomophila against Xanthomonas citri reduces citrus canker disease severity. Front Microbiol. 2020;11:1431

67. Qian X, Li S, Wu B, Wang Y, Ji N, Yao H, et al. Mainland and island populations of Mussaenda kwangtungensis differ in their phyllosphere fungal community composition and network structure. Sci Rep. 2020;10:1-14.

68. Adeleke BS, Babalola OO. The endosphere microbial communities, a great promise in agriculture. Int Microbiol. 2020;24:1-17.

69. Dubey A, Malla MA, Kumar A, Dayanandan S, Khan ML. Plants endophytes: unveiling hidden agenda for bioprospecting toward sustainable agriculture. Crit Rev Biotechnol. 2020;40(8):1210-31.

70. McNees CR, Law A, Moe L. Characterization of endophytic microbial communities in store-bought kale evaluated by different plant tissue homogenization methods. Phytobiomes J. 2020;4:211-6.

71. Chevreau E, Dousset N, Joffrion C, Richer A, Charrier A, Vergne E. Agroinfiltration is a key factor to improve the efficiency of apple and pear transformation. Sci Hortic. 2019:251:150-4.

72. Dinkeloo K, Cantero AM, Paik I, Vulgamott A, Ellington AD, Lloyd A. Genetic transformation technologies for the common dandelion Taraxacum officinale. Plant Methods. 2021;17:59.

73. Hwang H-H, Yu M, Lai E-M. Agrobacterium-mediated plant transformation: biology and applications. The Arabidopsis Book. 2017;15:e0186.

74. Li S, Cong Y, Liu Y, Wang T, Shuai Q, Chen N, et al. Optimization of Agrobacterium-mediated transformation in soybean. Front Plant Sci. 2017:8:246.

75. Bond DM, Albert NW, Lee RH, Gillard GB, Brown CM, Hellens RP, et al. Infiltration-RNAseq: transcriptome profiling of Agrobacterium-mediated infiltration of transcription factors to discover gene function and expression networks in plants. Plant Methods. 2016;12:41.

76. Ochoa-Fernandez R, Abel NB, Wieland FG, Schlegel J, Koch LA, Miller JB, et al. Optogenetic control of gene expression in plants in the presence of ambient white light. Nat Methods. 2020;17:717-25.

77. Nekrasov V, Staskawicz B, Weigel D, Jones JDG, Kamoun S. Targeted mutagenesis in the model plant Nicotiana benthamiana using Cas9 RNA-guided endonuclease. Nat Biotechnol. 2013;31:691-3.

78. Ma J, Xiang H, Donnelly DJ, Meng FR, Xu H, Durnford D, et al. Genome editing in potato plants by agrobacterium-mediated transient expression of transcription activator-like effector nucleases. Plant Biotechnol Rep. 2017;11:249-58. 
79. Demirer GS, Landry MP. Efficient transient gene knock-down in tobacco plants using carbon nanocarriers. Bio Protocol. 2021;11:e3891.

80. Rybka J, Mieloch A, Plis A, Pyrski M, Pniewski T, Giersig M. Assembly and characterization of $\mathrm{HBC}$ derived virus-like particles with magnetic core. Nanomaterials. 2019;9:155-66.

81. Pyrski M, Mieloch AA, Plewiński A, Basińska-Barczak A, Gryciuk A, Bociąg $P$, et al. Parenteral-oral immunization with plant-derived $\mathrm{HBCAg}$ as a potential therapeutic vaccine against chronic hepatitis B. Vaccines. 2019;7:211-22.

82. Chen Q, Dent M, Hurtado J, Stahnke J, McNulty A, Leuzinger K, et al. Transient protein expression by agroinfiltration in lettuce. Methods Mol Biol. 2016;1385:55-67.

83. Simmons CW, VanderGheynst JS, Nitin N. Attachment of Agrobacterium tumefaciens to leaf tissue in response to infiltration conditions. Biotechnol Prog. 2014;30:1137-44.

84. King JL, Finer JJ, McHale LK. Development and optimization of agroinfiltration for soybean. Plant Cell Rep. 2015;34:133-40.

85. Nanjareddy K, Arthikala MK, Blanco L, Arellano ES, Lara M. Protoplast isolation, transient transformation of leaf mesophyll protoplasts and improved Agrobacterium-mediated leaf disc infiltration of Phaseolus vulgaris: tools for rapid gene expression analysis. BMC Biotechnol. 2016;16:1-14.

86. Bakshi S, Sadhukhan A, Mishra S, Sahoo L. Improved Agrobacteriummediated transformation of cowpea via sonication and vacuum infiltration. Plant Cell Rep. 2011;30:2281-92.

87. Sharma R, Liang Y, Lee MY, Pidatala VR, Mortimer JC, Scheller HV. Agrobacterium-mediated transient transformation of sorghum leaves for accelerating functional genomics and genome editing studies. BMC Res Notes. 2020;13:116.

88. Lin L, Liu YG, Xu X, Li B. Efficient linking and transfer of multiple genes by a multigene assembly and transformation vector system. Proc Natl Acad Sci USA. 2003;100:5962-7.

89. Zheng L, Yang J, Chen Y, Ding L, Wei J, Wang H. An improved and efficient method of Agrobacterium syringe infiltration for transient transformation and its application in the elucidation of gene function in poplar. BMC Plant Biol. 2021;21:54.

90. Göritzer K, Goet I, Duric S, Maresch D, Altmann F, Obinger C, et al. Efficient $\mathrm{N}$-glycosylation of the heavy chain tailpiece promotes the formation of plant-produced dimeric IgA. Front Chem. 2020;8:346-57.

91. Margolin EA, Strasser R, Chapman R, Williamson A, Rybicki EP, Meyers AE. Engineering the plant secretory pathway for the production of next-generation pharmaceuticals. Trends Biotechnol. 2020;38:1034-44.

92. Kim BM, Lotter-Stark HCT, Rybicki EP, Chikwamba RK, Palmer KE. Characterization of the hypersensitive response-like cell death phenomenon induced by targeting antiviral lectin griffithsin to the secretory pathway. Plant Biotechnol J. 2018;16:1811-21.

93. Chen Z, Zheng W, Chen L, Li C, Liang T, Chen Z, et al. Green fluorescent protein- and Discosoma sp. red fluorescent protein-tagged organelle marker lines for protein subcellular localization in rice. Front Plant Sci. 2019;10:1421.

94. Hahn F, Korolev A, Sanjurjo Loures L, Nekrasov V. A modular cloning toolkit for genome editing in plants. BMC Plant Biol. 2020;20:179.

95. Esqueda A, Chen Q. Development and expression of subunit vaccines against viruses in plants. Methods Mol Biol. 2021;2225:25_38.
96. Castilho A, Schwestka J, Kienzl NF, Vavra U, Grünwald-Gruber C, Izadi S, et al. Generation of enzymatically competent SARS-CoV-2 decoy receptor ACE2-Fc in glycoengineered Nicotiana benthamiana. Biotechnol J. 2021;16:2000566.

97. Rattanapisit K, Shanmugaraj B, Manopwisedjaroen S, Purwono PB, Siriwattananon K, Khorattanakulchai N, et al. Rapid production of SARSCoV-2 receptor binding domain (RBD) and spike specific monoclonal antibody CR3022 in Nicotiana benthamiana. Sci Rep. 2020;10:17698.

98. Shanmugaraj B, Rattanapisit K, Manopwisedjaroen S, Thitithanyanont A, Phoolcharoen W. Monoclonal antibodies B38 and $\mathrm{H} 4$ produced in Nicotiana benthamiana neutralize SARS-CoV-2 in vitro. Front Plant Sci. 2020;11:589995.

99. Dicker M, Schoberer J, Vavra U, Strasser R. Subcellular targeting of proteins involved in modification of plant $\mathrm{N}$ - and $\mathrm{O}$-glycosylation. Methods Mol Biol. 2015;1321:249-67.

100. Strasser R. Plant protein glycosylation. Glycobiology. 2016;26:926-39.

101. Göritzer K, Maresch D, Altmann F, Obinger C, Strasser R. Exploring site-specific N-glycosylation of HEK293 and plant-produced human IgA isotypes. J Proteome Res. 2017;16:2560-70.

102. Cupil-Garcia V, Strobbia P, Crawford BM, Wang H-N, Zentella R, Sun T-P, et al. Applications of plasmonic nanoparticles for in vivo biosensing of plants. In: Ray K, Vo-Dinh T, Ho H-PA, editors., et al., Plasmonics of biology and medicine. Bellingham: SPIE; 2020. p. 42.

103. Ghorbanpour M, Fahimirad S. Plant nanobionics a novel approach to overcome the environmental challenges. In: Ghorbanpour M, Varma A, editors. Medicinal plants and environmental challenges. Cham: Springer; 2017. p. 247-57.

104. Wu H, Santana I, Dansie J, Giraldo JP. In vivo delivery of nanoparticles into plant leaves. Curr Protoc Chem Biol. 2017;9:269-84.

105. Lew TTS, Koman VB, Silmore KS, Seo JS, Gordiichuk P, Kwak SY, et al. Real-time detection of wound-induced $\mathrm{H}_{2} \mathrm{O}_{2}$ signalling waves in plants with optical nanosensors. Nat Plants. 2020;6:404-15.

106. Lew TTS, Park M, Cui J, Strano MS. Plant nanobionic sensors for arsenic detection. Adv Mater. 2021;33:2005683.

107. Wu H, Shabala L, Shabala S, Giraldo JP. Hydroxyl radical scavenging by cerium oxide nanoparticles improves Arabidopsis salinity tolerance by enhancing leaf mesophyll potassium retention. Environ Sci Nano. 2018;5:1567-83.

108. Dymek K, Panarese V, Herremans E, Cantre D, Schoo R, Toraño JS, et al. Investigation of the metabolic consequences of impregnating spinach leaves with trehalose and applying a pulsed electric field. Bioelectrochemistry. 2016;112:153-7.

109. Galindo FG, Yusof NL. New insights into the dynamics of vacuum impregnation of plant tissues and its metabolic consequences. J Sci Food Agric. 2015;95:1127-30.

\section{Publisher's Note}

Springer Nature remains neutral with regard to jurisdictional claims in published maps and institutional affiliations.

Ready to submit your research? Choose BMC and benefit from

- fast, convenient online submission

- thorough peer review by experienced researchers in your field

- rapid publication on acceptance

- support for research data, including large and complex data types

- gold Open Access which fosters wider collaboration and increased citations

- maximum visibility for your research: over $100 \mathrm{M}$ website views per year

At BMC, research is always in progress.

Learn more biomedcentral.com/submissions 